\title{
Increased Gene Expression and Production of Spinal Cyclooxygenase 1 and 2 during Experimental Osteoarthritis Pain
}

\author{
M. PROCHÁZKOVÁ ${ }^{1}$, P. ZANVIT ${ }^{2}$, T. DOLEŽAL ${ }^{1}$, L. PROKEŠOVÁ ${ }^{2}$, M. KRŠIAK ${ }^{1}$ \\ ${ }^{1}$ Department of Pharmacology, Third Faculty of Medicine, Prague, ${ }^{2}$ Institute of Immunology and \\ Microbiology, First Faculty of Medicine, Charles University, Prague, Czech Republic
}

Received October 29, 2007

Accepted April 2, 2008

On-line July 18, 2008

\begin{abstract}
Summary
Knowledge on the involvement of spinal COX-1 and COX-2 in pain due to osteoarthritis could be useful for better understanding of its pathogenesis and therapy. In this study we have investigated a long-term pattern of expression and production of spinal COX-1 and COX-2 in the model of osteoarthritis induced in rats by injection of monoiodoacetate (MIA) into the knee joint. MIA injection produced thermal hyperalgesia (assessed by the plantar test) and tactile allodynia (measured with von Frey hairs). The pain measures reached maximum on the 5 th day, then remained relatively stable. The expression of spinal COX-2 mRNA reached maximum on day 5 (5.2 times; $P<0.001)$ and remained increased until day 31 (4.9 times; $\mathrm{P}<0.001)$. Expression of spinal COX-1 mRNA increased gradually reaching maximum on the day 31 (4.5 times; $\mathrm{P}<0.001$ ) when the relative expression of both genes was almost equal. The production of both proteins was almost similar at the beginning of the experiment. The highest production of COX-2 protein was observed on day 5 after the induction of osteoarthritis (increased 3.9 times). The levels of COX-1 protein increased gradually with maximum on day 31 (3.4 times). The present findings indicate that not only expression of COX-2 mRNA but also that of COX-1 mRNA is significantly increased in the spine during osteoarthritis pain. Thus, in contrast to inflammatory pain, the upregulation of spinal COX-1 may be important in osteoarthritis pain.
\end{abstract}

\section{Key words}

Osteoarthritis • Cyclooxygenase (COX) • Pain • Spinal cord

\section{Corresponding author}

M. Procházková, Department of Pharmacology, 3rd Faculty of Medicine, Charles University, Ruská 87, 10034 Prague 10, Czech Republic. E-mail: michaela.prochazkova@lf3.cuni.cz, Fax: +420 267102461.

\section{Introduction}

Cyclooxygenases are the enzymes that catalyze the conversion of arachidonic acid to prostaglandins which play an important role in inflammation and pain. There are two identified cyclooxygenase (COX) isoenzymes: COX-1 and COX-2. COX-1 is the ,housekeeping" form, expressed by a wide variety of cells. COX-2 is highly inducible in response to inflammatory and noxious stimuli. Both cyclooxygenases are constitutively expressed in the spinal cord (Kaufmann et al. 1997).

The involvement of spinal COX-1 and COX-2 in various pain states is not fully understood. COX-2 gene expression and production in the spinal cord was significantly increased in rats with peripheral inflammation induced by intraplantar injection of Freund's complete adjutant (Beiche et al. 1996, Hay et al. 1997, Beiche et al. 1998). No increase of COX-1 gene expression and production in the spinal cord was found in this model which was associated with swelling, hyperalgesia and allodynia (Beiche et al. 1996, Hay et al. 1997, Beiche et al. 1998). In agreement with these findings, spinal COX-2 mRNA were markedly increased and spinal levels of COX-1 mRNA were not significantly altered in peripheral inflammation induced by intraplantar injection of carrageenan (Procházková et al. 2006).

Rats with streptozotocin-induced diabetes exhibited significantly increased levels of spinal COX-2 protein and activity along with hyperalgesia (Ramos et al. 2007). Intrathecal administration of COX-2 inhibitors has an anti-hyperalgesic effect on streptozotocin-induced 
mechanical hyperalgesia (Matsunaga et al. 2007). A sharp upregulation of spinal COX-2 was reported in the mouse model of amyotrophic lateral sclerosis (McGeer and McGeer 2002).

On the other hand, the expression of COX-2 mRNA in the spine was less dominant in postoperative pain model than in inflammatory pain, while expression of spinal COX-1 mRNA was significantly increased in postoperative pain (Procházková et al. 2006). The important role of COX-1 in the model of postoperative pain was also shown by Zhu et al. (2003).

Spinal COX-1 also appears to play a role in the model of neuropathic pain. Spinal COX-1 expression was increased after partial peripheral nerve transsection (Zhu and Eisenach 2003). The inhibition of COX-1 prevented the development of allodynia and hyperalgesia after peripheral nerve ligation (Hefferan et al. 2003).

One of the widespread painful disorders is osteoarthritis (OA), which is a degenerative joint disease. The joints are characterized by progressive degeneration of articular cartilage leading to inflammation and pain. In an attempt to peruse the pathophysiology of osteoarthritis, experimental models that mimic human disease have been developed (Pritzker 1994).

One of the most frequently used and one of the best characterized models of osteoarthritis is that of monoiodoacetate (MIA) induced OA. This model was first described twenty years ago by Kalbhen (1987). Monoiodoacetate inhibits the activity of glyceraldehyde3-phosphate dehydrogenase in chondrocytes and producing degeneration of the cartilage.

Knowledge on the involvement of spinal COX-1 and COX-2 in pain due to OA could be useful both for better understanding of its pathogenesis and for its therapy. In this study, therefore, we have investigated a long-term pattern of expression and production of spinal COX-1 and COX-2 in the model of monoiodoacetateinduced osteoarthritis. In particular, we have attempted to correlate changes in spinal cord production of COX-1 and COX-2 and expression of mRNA for COX-1 and COX-2 with the development of thermal hyperalgesia and tactile allodynia.

\section{Methods}

Animals

Male Wistar albino rats (weight 200-220 g) obtained from VÚFB Konárovice (Czech Republic) were used in all experiments. The animals were housed under standard laboratory conditions (in a temperaturecontrolled $\left(21 \pm 1^{\circ} \mathrm{C}\right)$ room with a normal 12-h light/dark cycle). Animals were fed a standard pelleted rat chow (ST-1; Velaz, Czech Republic) with water ad libitum throughout the whole experiment. Rats were acclimated to their surroundings over one week to eliminate the effect of stress before the experiment.

All experiments were approved by the Committee for Protection of Laboratory Animals of the 3rd Faculty of Medicine at Charles University and were concordant with IASP Committee for Research and Ethical Issues requirements (Zimmermann 1983).

\section{Induction of osteoarthritis}

For induction of osteoarthritis, rats were anesthetized with halothane (Narcotan, Zentiva). Eight rats per group received single injection of monoiodoacetate $(2 \mathrm{mg})$ (Sigma-Aldrich) into the right knee joint in a total volume of $25 \mu \mathrm{l}$. Control animals $(n=8)$ were injected $25 \mu 1$ of vehicle into the right knee joint under the same conditions.

\section{Paw withdrawal testing}

The response to noxious thermal stimulus was determined using thermal plantar device (Ugo Basile, Italy) according to the procedure described by Hargreaves et al. (1988) before and in defined times during 31 days after the injection of monoiodoacetate. Rats were placed to opaque plastic chambers $(22 \mathrm{~cm}$ in width $\mathrm{x} 17 \mathrm{~cm}$ in length $\mathrm{x} 14 \mathrm{~cm}$ in height) for $10 \mathrm{~min}$ prior to the start of the each experiment. This lets the animals accommodate to their new environment before testing. Movable infrared radiant heat source was placed directly under the plantar surface of the hind paw and the time taken for hind paw withdrawal was monitored. A cut-off time of $20 \mathrm{~s}$ was used in all experiments. Three tests were carried out at 10 min intervals and then the mean value was taken as the nociceptive threshold.

Following three baseline measurements, rats received intraarticular injection of monoiodoacetate or saline. In the defined times after injection of monoiodoacetate or saline, paw withdrawal latencies were recorded.

\section{von Frey hairs}

Tactile allodynia was measured with von Frey hairs (Ugo Basile, Italy). Animals were placed into wire mesh bottom cages and allowed to acclimatize prior the start of the experiment. Tactile allodynia was tested by 
touching the plantar surface of the animal's hind paw with von Frey hairs in ascending order of force until a paw withdrawal response was elicited. Each von Frey hair was applied to the paw for $5 \mathrm{~s}$ or until a response occurred. Once a withdrawal response was established, the paw was retested. The lowest amount of force required to elicit a response was recorded as withdrawal threshold in grams.

Following three baseline measurements, rats received intraarticular injection of monoiodoacetate or saline. Paw withdrawal thresholds were measured in defined times after the injection of monoiodoacetate or saline.

\section{Tissue preparation}

In four different times after monoiodoacetate or saline injection, animals (eight per group) were euthanized in halothane anesthesia. Lumbar section of the spinal cord was removed and given in RNAlater solution (Qiagen).

\section{RNA isolation}

Disruption and homogenization of small parts of the lumbar section of spinal cord weighing approximately $100 \mathrm{mg}$ stabilized with the RNAlater (Qiagen) was performed using Ultra-Turrax (Ika). Total RNA was isolated with the RNeasy lipid tissue isolation kit (Qiagen) according to the manufacturer's instruction. RNA integrity was determined by gel electrophoresis in $2 \%$ agarose gel stained with ethidium bromide. The purity of the RNA was assessed by the ratio of absorbance at $260 \mathrm{~nm}$ and $280 \mathrm{~nm}$. RNA was stored in aliquots at $-70{ }^{\circ} \mathrm{C}$ until used for reverse transcription.

\section{Reverse transcription}

RNA samples were reverse transcribed using RT buffer, $25 \mathrm{mM} \mathrm{MgCl}, 10 \mathrm{mM}$ dNTPs (2.5 $\mathrm{mM}$ of each), $50 \mu \mathrm{M}$ random hexamers, RNase inhibitor $(20 \mathrm{U} / \mu \mathrm{l})$ and reverse transcriptase $(50 \mathrm{U} / \mu \mathrm{l})$, all from Applied Biosystems. The mix was aliquoted into individual tubes and RNA was added. Samples were incubated for $10 \mathrm{~min}$ at $25^{\circ} \mathrm{C}, 30 \mathrm{~min}$ at $48{ }^{\circ} \mathrm{C}$ and then for $5 \mathrm{~min}$ at $95^{\circ} \mathrm{C}$.

\section{Real-time PCR}

A reaction mix for real-time PCR was made with

TaqMan Universal PCR master mix, water and Assays on Demand gene expression products (all Applied Biosystems).

Reaction mix was aliquoted to the wells on a real-time PCR plate. Each sample was made in duplicate. A volume of $5 \mu 1$ of cDNA was added to each well. A no- template control contained water instead of cDNA. PCR reaction was run on ABI PRISM 7300 (ABI PRISM 7300 SDS analytical cycler, Applied Biosystems) using standard conditions.

Expression of COX-1 and COX-2 was normalized to RNA loading for each sample using the $\beta 2$-microglobulin as an internal standard. The quantity of mRNA was given as $2^{-\Delta \Delta c t} . \Delta \Delta$ ct was calculated as follows: $\Delta \Delta c t=\Delta \mathrm{ct}($ gene of interest $)-\Delta \mathrm{ct}($ endogenous control) .

\section{ELISA}

For detection of antigens, sandwich enzymelinked immunosorbent assay (ELISA) was used. Microtiter NUNC plates (Schoeller) were coated with monoclonal antibody specific for cyclooxygenase 1 (Alpha Diagnostic) and for cyclooxygenase 2 (Kamiya Biomedical Company) diluted in coating buffer and incubated overnight.

After $24 \mathrm{~h}$ the plates were washed two times with washing buffer PBS (phosphate buffered saline) and two times with PBST (PBS containing $0.05 \%$ Tween 20, Sigma-Aldrich). Each well was then filled with PBST and incubated for one hour at room temperature to prevent non-specific adsorption of protein to the well surfaces. During this time, samples from spinal cord of monoiodoacetate-injected or control animals were homogenized in $5 \%$ FBS (fetal bovine serum, SigmaAldrich) and then added to the wells. Two hours after this incubation at room temperature, the plates were washed two times with PBS and two times with PBST (PBS containing $0.05 \%$ Tween 20, Sigma-Aldrich).

The secondary biotinylated antibodies (Acris Antibodies) were added to the wells and incubated for next two hours. The plates were then washed, followed by incubation of 1:1000 dilution of streptavidin (Beckman Coulter) for $20 \mathrm{~min}$. After washing the coated well, TMB (tetramethylbenzidine, Sigma-Aldrich) and citric buffer with peroxide were added.

For development of the color reaction the plates were incubated in the dark and the reaction was stopped by the addition of $\mathrm{H}_{2} \mathrm{SO}_{4}$ to each well. The color intensity was determined at $450 \mathrm{~nm}$ on Multiscan RC reader. Results are expressed as stimulation index (OD of monoiodoacetate treated vs. OD of control animals).

\section{Drugs}

Monoiodoacetate was purchased from SigmaAldrich and halothane (Narcotan) was obtained from Zentiva. 


\section{Statistical analysis}

All results are expressed as mean values \pm S.E.M. Statistical analysis was carried out using twoway repeated measures ANOVA with a post-hoc StudentNewman-Keuls test in the case of repetitive testing of paw withdrawal. $\mathrm{P}<0.05$ was accepted as significant. The evaluation of real-time PCR data was done by one-way ANOVA with a post-hoc Turkey's test using $2^{-\Delta \Delta c t}$ values of each samples. $\mathrm{P}<0.05$ value was considered significant. Data from ELISA method are presented as stimulation index and were analyzed using unpaired $\mathrm{t}$-test. The results were considered significant if $\mathrm{P}$ value was less than 0.05 .

\section{Results}

Effect of monoiodoacetate on paw withdrawal latency

Paw withdrawal latencies were measured before and in defined times after application of monoiodoacetate or saline. Intraarticular injection of monoiodoacetate into the right knee joint produced marked and significant reduction of paw withdrawal latencies to noxious radiant heat stimuli. Decreased paw withdrawal latencies were evident from the first day following injection of monoiodoacetate, with the maximum on day 5 after induction of osteoarthritis (statistically significant at all observed times compared to baseline and to control animals; $\mathrm{P}<0.001$ ). The paw withdrawal latencies remained decreased until day 31 (Fig. 1).

\section{Effect of monoiodoacetate on tactile allodynia}

Tactile allodynia was measured with von Frey hairs before and following intraarticular injection of monoiodoacetate or saline. The injection of monoiodoacetate into the right knee joint induced marked allodynia. The onset of allodynia was evident from the first day following injection of monoiodoacetate. Figure 2 shows that tactile allodynia in the monoiodoacetate-injected knee joints reaches the maximum on day 5 and was observed throughout the experiment (statistically significant at all observed times compared to baseline and to control animals, $\mathrm{P}<0.001$ ).

Expression of COX-1 and COX-2 mRNA in the spinal cord after induction of osteoarthritis

Expression of COX isoenzymes was measured at four different times. First day after monoiodoacetate injection, spinal levels of COX-1 mRNA and COX-2

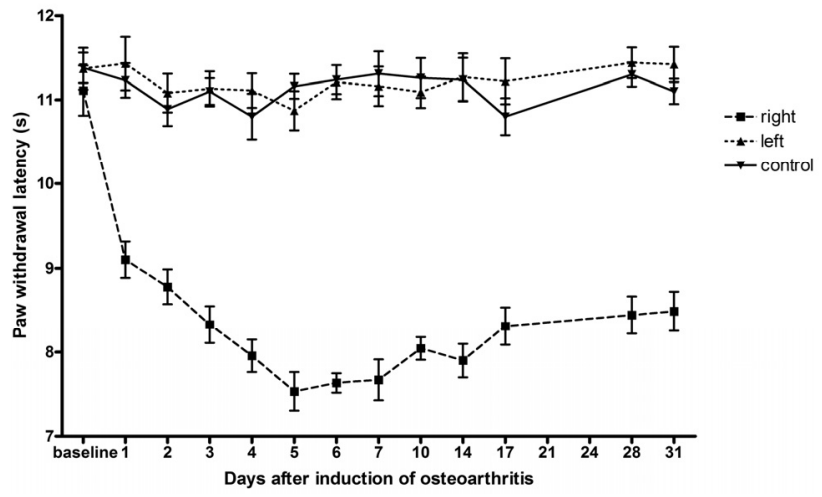

Fig. 1. Paw withdrawal latencies to a noxious radiant heat stimulus before and after the induction of osteoarthritis. Osteoarthritis reduced paw withdrawal latencies in the right (monoiodoacetate-injected) hind paws. Control animals exhibited no differences in paw withdrawal latencies. Withdrawal latencies of the left (uninfected) paws of osteoarthritis rats did not differ from those of control. The data represent observations from 8 animals per group displayed as means \pm S.E.M. $(P<0.001$ at all observed times compared to baseline and to control animals).

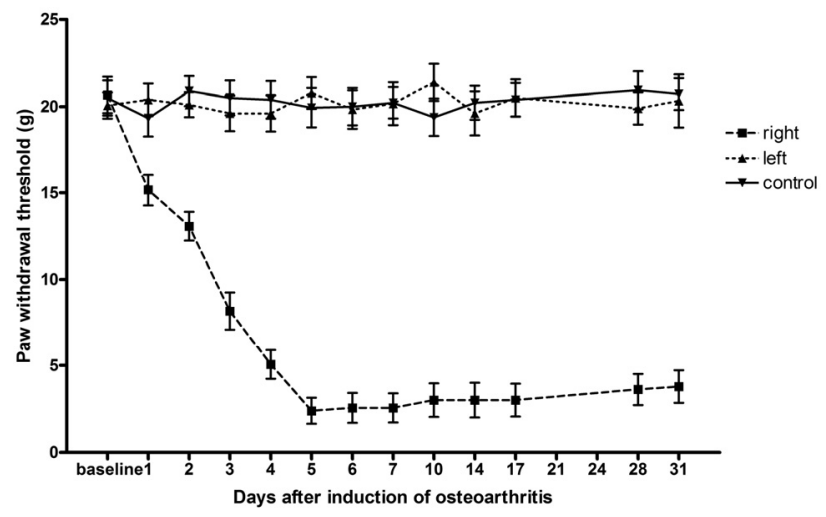

Fig. 2. Paw withdrawal thresholds to von Frey hairs before and after the induction of osteoarthritis. Paw withdrawal thresholds to von Frey hairs were significantly decreased from the first day after monoiodoacetate injection into the right knee joint. Control and uninfected (left) paws were not altered during the whole testing period. Results are expressed as median force in grams \pm S.E.M. required to induce paw withdrawal in 8 animals per group $(P<0.001$ at all observed times compared to baseline and to control animals).

mRNA were moderately increased (2.3 and 2.6 times, respectively; $\mathrm{P}<0.05$ ). The expression of spinal COX-2 mRNA was much higher on day 5 (5.2 times; $\mathrm{P}<0.001)$ and remained increased at this level until the day 31 (4.9 times; $\mathrm{P}<0.001)$. On the other hand, expression of spinal COX-1 mRNA increased gradually during the whole testing period reaching maximum on the day 31 (4.5 times; $\mathrm{P}<0.001$ ) when the relative expression of both genes was almost equal. All results are expressed in comparison with control animals (Fig. 3). 


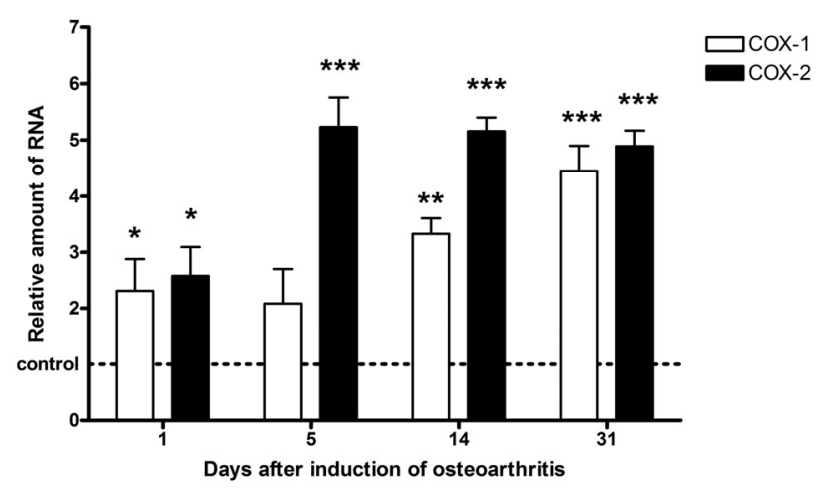

Fig.3. Relative expression of cyclooxygenase 1 and cyclooxygenase 2 in lumbar section of spinal cord 1, 5, 14 and 31 days after the induction of osteoarthritis (induced by injection of monoiodoacetate) as determined by real-time PCR. Each column represents observations from 8 animals displayed as means \pm S.E.M. Asterisks indicate significant difference between monoiodoacetate injected and control animals at respective timepoints (* $\mathrm{P}<0.05 ; * * \mathrm{P}<0.01$ and $* * * \mathrm{P}<0.001$ ).

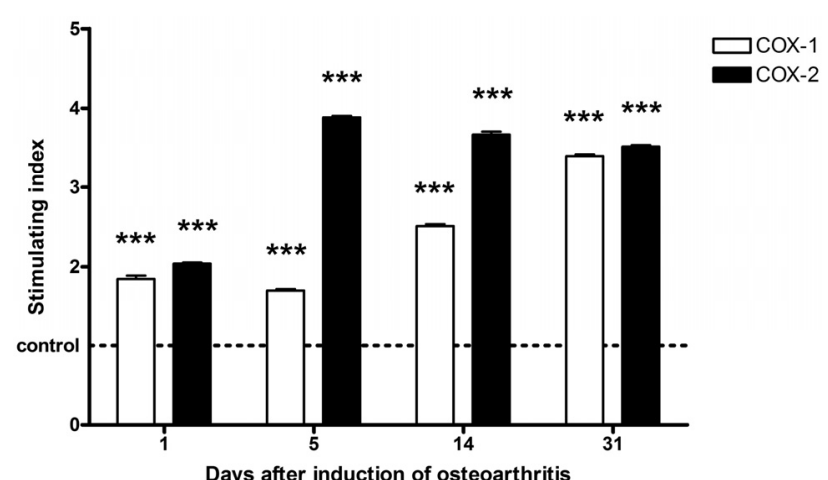

Fig. 4. Production of cyclooxygenase 1 and cyclooxygenase 2 proteins in lumbar section of spinal cord 1, 5, 14 and 31 days after induction of osteoarthritis (induced by injection of monoiodoacetate) as determined by ELISA method. Results (mean values \pm S.E.M.) are expressed as stimulation index (OD of monoiodoacetate treated vs. OD of control animals). Asterisks indicate significant difference between production of COX proteins in monoiodoacetate-injected and control animals at four different times $(* * * \mathrm{P}<0.001)$.

\section{Production of COX-1 and COX-2 proteins after induction of osteoarthritis}

The production of spinal COX proteins was comparable to the expression results. The production of COX-1 and COX-2 proteins was almost similar at the beginning of the experiment (1.9 and 2.0 times, respectively; $\mathrm{P}<0.001)$. The highest production of $\mathrm{COX}-2$ protein was observed on day 5 after the induction of osteoarthritis (increased 3.9 times; $\mathrm{P}<0.001$ ). The levels of COX-1 protein increased gradually from the 5 th day after induction of osteoarthritis (1.7 times; $\mathrm{P}<0.001)$ with maximum on day 31 (3.4 times; $\mathrm{P}<0.001)$. Results are expressed as stimulation index (OD of monoiodoacetatetreated vs. OD of control animals) (Fig. 4).

\section{Discussion}

Monoiodoacetate injection produced pain as measured by von Frey thresholds and paw withdrawal latencies in the plantar test. The pain measures reached maximum on the 5th day, then remained relatively stable. Expression and production of spinal COX-2 was rapidly increased in parallel to pain measures reaching maximum on the 5 th day and then remained relatively stable. On the other hand, the expression and production of spinal COX-1 mRNA increased at a slower pace but 31 days after the induction of osteoarthritis there was almost no difference between relative amount of $\mathrm{COX}-1$ and COX-2 mRNA.

The present results indicate that osteoarthritis pain has different patterns of expression of spinal mRNA for COX-1 and COX-2 compared with chronic inflammatory or postoperative pain. Expression and production of spinal COX-2 were significantly increased 22 days after the induction of arthritis by CFA (Complete Freund's Adjuvant) while spinal COX-1 mRNA and protein levels remained unchanged at this time (Beiche et al. 1996, Beiche et al. 1998). In contrast, COX-1 might play a more important role in postoperative pain. Expression of spinal COX-1 mRNA raised gradually after rat paw incision and 6 hours after the surgery there was no difference between relative amount of COX-1 and COX-2 mRNA in the spinal cord (Procházková et al. 2006).

The increased expression and production of spinal COX-1 in some types of pain may have therapeutic implications. The lack of analgesic effect of intrathecally administered selective inhibitor of COX-2 (NS-398) in the model of postoperative pain induced by skin incision suggest that spinal COX-2 might play a less important role in this type of pain (Yamamoto and Sakashita 1999). Intrathecal administration of COX-1 inhibitors, but not of COX-2 inhibitor, dose-dependently reduced pain in the model of postoperative pain (Zhu et al. 2003). Perioperative intrathecal administration of COX-1 inhibitors (COX-1 preferring inhibitor ketorolac and COX-1 selective inhibitor SC-560), but not of selective COX-2 inhibitor (NS-398), reduced paw incision induced hypersensitivity in the model of postoperative pain in rats (Zhu et al. 2005). Intrathecal administration of selective COX-1 inhibitor (SC-560), but not selective inhibitor of COX-2 (NS-398), restores normal exploratory activity (rearing behavior) after laparotomy (Martin et al. 2006).

The increased expression of spinal COX-1 mRNA found in the present study corroborates other 
findings suggesting important role of this enzyme in osteoarthritis. Knorth et al. (2004) demonstrated the important role of synovial COX-1 in patients with primary osteoarthritis.

The expression of COX-1 and COX-2 mRNA from synovial tissue from patients with osteoarthritis or from patients with inflammatory arthritis (rheumatoid arthritis) was compared by Siegle et al. (1998). The expression of COX-2 was found to be elevated in both groups of the patients, but the difference in expression of both cyclooxygenases was more evident in the group of patients with rheumatoid arthritis. The amount of COX-2 mRNA was significantly higher in patients with rheumatoid arthritis compared with patients with osteoarthritis.

The expression of both, COX-1 and COX-2 mRNA, was detected in cells from synovial fluid of patients with acute and chronic arthritis. COX-1 was the most abundant isoform with the strong immunostaining observed in a special fraction of mononuclear cells (Iniguez et al. 1998).

In summary, the present findings indicate that not only expression and production of COX-2 but also that of COX-1 is significantly increased in the spine during osteoarthritis pain. In contrast to inflammatory pain, the increased expression and production of spinal COX-1 might play an important role in osteoarthritis pain.

\section{Conflict of Interest}

There is no conflict of interest.

\section{Acknowledgements}

This work was supported by research grants VZ MSM0021620816.

\section{References}

BEICHE F, SCHEUERER S, BRUNE K, GEISSLINGER G, GOPPELT-STRUEBE M: Up-regulation of cyclooxygenase-2 mRNA in the rat spinal cord following peripheral inflammation. FEBS Lett 390: 165-169, 1996.

BEICHE F, BRUNE K, GEISSLINGER G, GOPPELT-STRUEBE M: Expression of cyclooxygenase isoforms in the rat spinal cord and their regulation during adjuvant-induced arthritis. Inflamm Res 47: 482-487, 1998.

HARGREAVES K, DUBNER R, BROWN F, FLORES C, JORIS J: A new and sensitive method for measuring thermal nociception in cutaneous hyperalgesia. Pain 32: 77-88, 1988.

HAY CH, TREVETHICK MA, WHEELDON A, BOWERS JS, BELLEROCHE JS: The potential role of spinal cord cyclooxygenase-2 in development of Freund's complete adjuvant-induced changes in hyperalgesia and allodynia. Neuroscience 78: 843-850, 1997.

HEFFERAN MP, O'RIELLY DD, LOOMIS CW: Inhibition of spinal prostaglandin synthesis early after L5/L6 nerve ligation prevents the development of prostaglandin-dependent and prostaglandin-independent allodynia in the rat. Anesthesiology 99: 1180-1188, 2003.

INIGUEZ MA, PABLOS JL, CARREIRA PE, CABRE F, GOMEZ-REINO JJ: Detection of COX-1 and COX-2 isoforms in synovial fluid cells from inflammatory joint diseases. Br J Rheumatol 37: 773-778, 1998.

KALBHEN DA: Chemical model of osteoarthritis - a pharmacological evaluation. J Rheumatol 14: 130-131, 1987.

KAUFMANN WE, ANDREASSON KL, ISAKSON PC, WORLEY PF: Cyclooxygenases and the central nervous system. Prostaglandins 54: 601-624, 1997.

KNORTH H, DORFMULLER P, LEBERT R, SCHMIDT WE, WITTENBERG RH, HEUKAMP M, WIESE M, WILLBURGER RE: Participation of cyclooxygenase-1 in prostaglandin $\mathrm{E}_{2}$ release from synovitis tissue in primary osteoarthritis in vitro. Osteoarthritis Cartilage 12: 658-666, 2004.

MARTIN TJ, BUECHLER NL, EISENACH JC: Intrathecal administration of a cyclooxygenase-1, but not a cyclooxygenase-2 inhibitor, reverses the effects of laparotomy on exploratory activity in rats. Anesth Analg 103: 690-695, 2006.

MATSUNAGA A, KAWAMOTO M, SHIRAISHI S, YASUDA T, KAJIYAMA S, KURITA S, YUGE O: Intrathecally administered COX-2 but not COX-1 or COX-3 inhibitors attenuate streptozocin-induced mechanical hyperalgesia in rats. Eur J Pharmacol 554: 12-17, 2007. 
MCGEER PL, MCGEER EG: Inflammatory processes in amyotrophic lateral sclerosis. Muscle Nerve 26: 459-470, 2002.

PRITZKER KP: Animal models for osteoarthritis: processes, problems and prospects. Ann Rheum Dis 53: 406-420, 1994.

PROCHÁZKOVÁ M, DOLEŽAL T, SLÍVA J, KRŠIAK M: Different patterns of spinal cyclooxygenase-1 and cyclooxygenase-2 mRNA expression in inflammatory and postoperative pain. Basic Clin Pharmacol Toxicol 99: 173-177, 2006.

RAMOS KM, JIANG Y, SVENSSON CI, CALCUTT NA: Pathogenesis of spinally mediated hyperalgesia in diabetes. Diabetes 56: 1569-1576, 2007.

SIEGLE I, KLEIN T, BACKMAN JT, SAAL JG, NUSING RM, FRITZ P: Expression of cyclooxygenase 1 and cyclooxygenase 2 in human synovial tissue: differential elevation of cyclooxygenase 2 in inflammatory joint diseases. Arthritis Rheum 41: 122-129, 1998.

YAMAMOTO T, SAKASHITA Y: The role of the spinal opioid receptor like1 receptor, the NK-1 receptor, and cyclooxygenase-2 in maintaining postoperative pain in the rat. Anesth Analg 89: 1203-1208, 1999.

ZHU X, CONKLIN D, EISENACH JC: Cyclooxygenase-1 in the spinal cord plays an important role in postoperative pain. Pain 104: 15-23, 2003.

ZHU X, CONKLIN DR, EISENACH JC: Preoperative inhibition of cyclooxygenase-1 in the spinal cord reduces postoperative pain. Anesth Analg 100: 1390-3, 2005.

ZHU X, EISENACH JC: Cyclooxygenase-1 in the spinal cord is altered after peripheral nerve injury. Anesthesiology 99: 1175-1179, 2003.

ZIMMERMANN M: Ethical guidelines for investigations of experimental pain in conscious animals. Pain 16: 109-110, 1983. 